\title{
Influências do Capital no agir político
}

\section{Influences of Capital on Political Action}

\author{
RAFAEL LEITE FERREIRA CABRAL ${ }^{1}$
}

\begin{abstract}
Resumo: O Capital de Karl Marx tem como principais legados a desmistificação da legitimidade pressuposta do sistema capitalista e a explicitação de sua lógica exploratória. Como a lógica do império capitalista impregnou quase todas as potencialidades humanas, dificultando a dissociação do "homem" forjado pelo sistema capitalista do ser humano, busca-se verificar quais influências e condicionamentos do modo de produção e da ideologia capitalista podem ser identificadas no agir político e nas tomadas de decisões coletivas. Com efeito, neste ensaio é explorada a analogia entre a alienação do trabalhador de si mesmo e dos demais humanos no processo de trabalho e a alienação do cidadão no processo político forjado apenas na eleição e representação. Ela tem como efeitos afastar o cidadão dos demais, das questões políticas e comunitárias, bem como impedir que se discuta essa estrutura pressuposta de legitimação simbólica corporificada no voto.
\end{abstract}

Palavras-chave: Capitalismo. Política. Alienação. Trabalhador. Cidadão.

\begin{abstract}
Karl Marx's Capital has as its main legacies the demystification of the presupposed legitimacy of the capitalist system and the explication of its exploratory logic. As the logic of the capitalist empire impregnated almost all human potentialities, making it difficult to dissociate the "man" forged by the capitalist system of the human being, it seeks to verify which influences and conditionings of the mode of production and capitalist ideology can be identified in political action and in collective decision-making. Indeed, in this essay the analogy between the alienation of the worker from himself and other humans in the labor process and the alienation of the citizen in the political process forged only in election and representation. It has the effect of alienating the citizen from others, from political and community issues, and from preventing the discussion of this presupposed structure of symbolic legitimation embodied in the vote.
\end{abstract}

Keywords: Capitalism. Politics. Alienation. Worker. Citizen.

\section{Introdução}

Karl Marx em sua obra O Capital, a partir de sua análise materialista-histórica, faz exposição desmistificadora da origem violenta do capital demonstrando a "acumulação primitiva", consistente no "processo histórico de separação entre produtor e meio de produção" perpetrada em quase todos os países, com suas peculiaridades inerentes, mediante o deslocamento súbito e violento de grandes massas de humanos "[...] de seus meios de subsistência e lançadas no mercado de trabalho como proletários absolutamente livres. A expropriação da terra que antes

\footnotetext{
${ }^{1}$ Possui graduação em Direito pela Pontifícia Universidade Católica do Paraná-PUCPR (2004). Pósgraduado em Direito aplicado pela Escola do Ministério Público do Estado do Paraná (2005) e pela Escola da Magistratura do Estado do Paraná (2006). Atualmente é advogado sócio do escritório Wypych, Broetto \& Advogados Associados e está cursando (2015) pós-graduação em Direito Processual Civil. Mestre em Filosofia pela UNIOESTE. E-mail: rafaellfcabral@hotmail.com.
} 
pertencia ao produtor rural, ao camponês, constitui a base de todo o processo" (MARX, 2011, p. 631/632).

Marx expõe, pormenorizadamente, a lógica de cada um dos pilares do capital, como a mercadoria, a propriedade privada, o trabalhador, o dinheiro, o mercado, a mais-valia, a produção, a exploração da força de trabalho, etc., cuja atuação orquestrada tem como consequência a exploração e alienação do trabalhador, bem como a concentração de riquezas.

A desmistificação da origem do capital e a descrição pormenorizada da sua lógica consubstancia o grande legado deixado por Marx nessa obra, pois permite, de um lado, inquinar a legitimidade pressuposta do sistema capitalista como desdobramento natural e irreversível da evolução social ${ }^{2}$. Por outro lado, ao escancarar como atuam cada uma das premissas do processo capitalista e suas consequências deletérias, Marx fornece instrumentos fundamentais para $\mathrm{o}$ desenvolvimento de novas críticas, de soluções ou até mesmo de superação do sistema capitalista.

Apesar da grande influência marxista que sustentou teórica e ideologicamente o advento de Estados Nacionais que se proclamavam socialistas, mas implementavam o totalitarismo; é inegável que hoje a expansão mundial da ideologia e do modo de produção capitalista, cujo domínio, em quase todas as facetas e potencialidades do homem, dificulta/impossibilita a distinção do 'homem' do 'homem capitalista' (condicionado e forjado pelo sistema capitalista).

Diante do império do sistema capitalista qualquer análise de questões políticas, sociais, comportamentais e etc. tem como premissa conhecer a essência do sistema, sua lógica imanente, sua estrutura ideológica e legitimadora, bem como considerar suas inexoráveis influências e condicionamentos.

O agir político do homem, desde a atuação nas polis gregas até o advento das sociedades capitalistas modernas, se transformou radicalmente, especialmente sua cooptação/instrumentalização pela ideologia capitalista, de modo que cada vez mais a tomada de decisões políticas é monopólio de poucos.

Nesse passo, a partir do recorte teórico que se propõe e observando os limites do presente trabalho, serão apontados, sumariamente, quais características do modo de produção e da ideologia capitalista é possível identificar no agir e nas tomadas de decisões políticas.

\footnotetext{
${ }^{2}$ É oportuno lembrar a perspicaz observação do Professor Rosalvo Schütz “... poder questionar algo a partir de sua gênese constituidora, é preciso entender suas condições de possibilidade, ou, em outras palavras, a processualidade social e humana pressuposta. $\mathrm{O}$ mérito da reflexão de Marx em relação ao tema, no escrito em questão, é que, em vez de afirmar que a propriedade privada é a causa da alienação, como faziam os socialistas utópicos, afirma o contrário: que o trabalho alienado é a causa (condição de possibilidade) da propriedade privada" (SCHÜTZ, 2008).
} 


\section{O animal social, o ser genérico e o trabalhador alienado}

Os animais agem precipuamente por instinto e experiências individualizadas, e o homem se deles se diferencia principalmente pela linguagem, pela transmissão de conhecimento e experiências, produzindo, assim, o conhecimento humano intersubjetivo, histórico, relacional e cultural.

Essa característica relacional, de convívio, entre homens amparou a expressão de Aristóteles segundo a qual o homem é um animal político, que Marx transmuda para ser social ${ }^{3}$. Desde Aristóteles, portanto, é inegável que a intersubjetividade, o convívio entre diferentes, consubstancia a principal característica do agir político.

Marx desenvolve seu conceito de ser genérico como 'essencialmente social e autoconsciente em sua atividade produtiva (objetivadora, intersubjetiva e carecedora de um meio externo-objetivo para se realizar), (WARTENBERG, 1982). De modo que 'a universalidade definidora da espécie (Gattung) humana é uma universalidade concreta, vivida efetivamente nas relações sociais estabelecidas entre os indivíduos e entre estes e o meio natural.' (TAVARES, 2014, p. 5).

Como ainda demonstra Tavares (2014, p. 6):

O problema maior da sociedade dos produtores de mercadorias é, precisamente, a degeneração do humano em mercadoria [...]. A crítica desta degeneração não está suspensa no ar, mas atada aos conceitos de estranhamento e de alienação. Estes, tampouco, flutuam no éter conceitual, mas remetem precisamente ao ser genérico.

A perspectiva intersubjetiva, de convivência própria do agir político, contudo, é sufocada no processo de produção capitalista, pois como bem demonstra Marx a alienação do trabalhador ocorre, precipuamente, sob ao menos dois aspectos interrelacionados:

1) a relação do trabalhador com o produto do trabalho como um objeto estranho e poderoso sobre ele. Esta relação é, ao mesmo tempo, a relação com o mundo exterior sensível, com os objetos da natureza, como um mundo alheio que se lhe defronta e hostilmente; 2) a relação do trabalho com ato de produção no interior do trabalho. Essa relação é a relação do trabalhador com sua própria atividade [atividade] estranha não pertencente a ele, atividade como miséria, a força como impotência, a procriação como castração. A energia espiritual e física própria do trabalhador, a sua vida pessoal - pois o que é a vida senão atividade - como uma atividade voltada contra ele mesmo, independente dele, não pertencente a ele. O estranhamento-de-si [auto-alienação], tal qual acima o estranhamento da coisa. (MARX, 2008, p. 83).

\footnotetext{
${ }^{3}$ Marx faz expressa citação de Aristóteles, vide, MARX, 1996, p. 443.
} 
A consequência direta da alienação do homem

[...] de o homem estar estranhado do produto do seu trabalho, de sua atividade vital e de seu ser genérico, é o estranhamento do homem pelo [próprio] homem. Quando o homem está frente a si mesmo, defronta-se com ele o outro homem. consigo [...]. Em geral, a questão de que o homem está estanhado [alienado] do seu ser genérico quer dizer que um homem está estranhado [alienado] do outro, assim como cada um deles [está estranhado] da essência humana (MARX, 2008, p. 85-86).

Como bem pontua o Professor Rosalvo Schütz "O estranhamento e a indiferença dos homens na relação uns com os outros se mostra, portanto, como sendo o fundamento social mais profundo da alienação" (SCHÜTZ, 2008).

Desse modo, no sistema capitalista 'A relação entre as pessoas se esconde atrás da relação entre as coisas”, como bem sintetizou Marx (1996, p. 31). Em razão de o homem alienar a si mesmo e, por conseguinte, dos outros, no sistema de produção capitalista fica obstada a troca de ideias, a convivência fértil, o reconhecimento do outro, o que constitui premissas do agir político.

O trabalho, no modelo de produção capitalista, é externo ao trabalhador, não integra sua natureza, de modo que dificulta o desenvolvimento das potencialidades humanas ${ }^{4}$ (questão da precarização dos empregos e o desenvolvimento das ideais). O processo de trabalho exaure o trabalhador, o afasta da reflexão sobre as questões da comunidade.

O liberalismo individualista e, por conseguinte, as democracias liberais próprio do sistema capitalista se vincula à fins exclusivamente individualistas e privados, contrastando com o agir político essencialmente coletivo e intersubjetivo, com o bem comum e virtudes cívicas que são pressupostos para uma democracia sólida e substancial.

Tal questão é ainda mais sensível quando se analisa os efeitos do capital sobre os procedimentos Estatais de tomada de decisões coletivas.

O procedimento democrático forjado pelos Estados a partir da eleição e representação consubstancia franco processo de alienação do cidadão das questões políticas e de si mesmo. Isso porque política é contato, a persuasão, o convívio entre diferentes, e o homem quando simplesmente deposita o seu voto na urna se aliena dos demais e de suas concepções políticas.

\footnotetext{
${ }^{4}$ Karl Marx bem demonstra o círculo vicioso decorrente da alienação do trabalhador em seu objeto que "se expressa pelas nacional-econômicas, em que quanto mais o trabalhador produz, menos tem para consumir; quanto mais valores cria, mais sem-valor e indigno ele se torna; quanto mais bem formado o seu produto, tanto mais deformado ele fica; quanto mais civilizado seu objeto, mais bárbaro o trabalhador; que quanto mais poderoso o trabalho, mais impotente o trabalhador se torna; quanto mais rico de espírito o trabalho, mais pobre de espírito e servo da natureza se torna o trabalhador" (MARX, 2008, p. 82).
} 
A alienação do cidadão, eleitor alienado de si mesmo e das relações humanas faz com que ele não mais discuta a legitimidade dessa forma de construção das decisões políticas, em face dessa estrutura pressuposta de legitimação decorrente da sua suposta participação na tomada de decisões coletivas.

Com efeito, é possível fazer uma analogia entre a alienação do trabalhador de si mesmo e dos demais humanos no processo de trabalho e a alienação do cidadão no processo político circunscrito à eleição e à representação, pois o processo político inteiro passa a ser visto apenas com uma parte (o voto) distanciando, assim, o cidadão da política.

\section{A formação do capital e do político. Trabalhador e eleitor livre.}

Marx afirma que o capitalista só passa a existir quando "o possuidor de meios de produção e de subsistência encontra o trabalhador livre como vendedor de sua força de trabalho no mercado", transformando a força de trabalho em uma mercadoria que o trabalhador, por ser livre, pode dispor (MARX, 1996, p. 288).

A origem do capital, portanto, exigiu uma massa de trabalhadores 'livres' desvinculados dos meios de produção (terra), dispostos a alienarem suas forças de trabalho como mercadoria (MARX, 2011, p. 631-632). Do mesmo modo, a ascensão da burguesia ao poder político, em especial pós Revolução Francesa, precisava de uma massa de cidadãos livres do julgo do déspota, livres para votar em seu representante a fim de assim legitimar a tomada e assegurar a perpetuação do poder da classe revolucionaria.

A legitimidade do poder político forjado pelos Estados Nacionais tem origem na outorga ao cidadão do direito de sufrágio, no direito de votar e ser votado. Contudo, ao mesmo tempo que foi concedido esse direito ao cidadão para garantir suposta legitimidade do processo político (todo poder emana do povo), tal processo amparado exclusivamente na eleição e na representação afastou o cidadão das questões políticas.

Isso porque, de um lado, ao reduzir o processo de decisões políticas à um único momento (eleição), afastou o cidadão do debate, da vivência política, cotidiana. Por outro lado, para que o cidadão se insira na política ele tem que superar uma série de obstáculos impostos pela lógica previamente estabelecida.

Com efeito, podemos apresentar a seguinte analogia: o cidadão de agente político direto (como produtor direto de mercadoria) foi transformado em um mero repassador de força/legitimidade política (é a força de trabalho do que cria valor), por meio do voto (mercadoria), ao governante (capitalista), que passa a decidir as questões políticas de modo a perpetuar a classe dominante a que pertence (fluxo ininterrupto) no poder. 
Assim, como faz o capitalista, quem detêm a mais-valia política, produzida pelo povo, nas suas mãos instrumentalizando-a para seus fins específicos.

\section{Político como mercadoria}

Outra questão com forte inspiração na ideológica capitalista que podemos analisar nas democracias contemporâneas é a forma como são selecionados os políticos.

O crescimento político, desde sua raiz político-partidária, de quem pretenda participar do sistema exige uma boa dose de dinheiro, de aceitação dos "caciques" políticos e alcance nos meios de comunicação. Esses obstáculos criados para ascensão ao mundo político estatal são, a rigor, filtros de corrupção do sistema político que só admite a projeção política dos seus. Com efeito, a disputa eleitoral exige a submissão, o comprometimento, ao capital, ao apadrinhamento, e/ou à mídia.

Nesse sentido, fica evidente, que a eleição e, por conseguinte, a representação, a despeito de constituírem pressupostos fundamentais para a democracia, afastam o cidadão do exercício do seu poder, tendo em vista o custo de o cidadão membro de uma sociedade capitalista e individualista participar do sistema político.

Com efeito, os candidatos se transformaram em mercadorias, produtos talhados a partir de muito dinheiro e propaganda. Ganha a eleição, em regra, quem mais investiu e se comprometeu com os agentes corruptores, de modo a perpetuar o monopólio das decisões políticas.

A eleição não tem qualquer vínculo com a tomada de decisão política, significa apenas quem vai tomar a decisão, por outro lado possui pouco vínculo com qual decisão este alguém vai tomar. No único momento que é dado ao cidadão se manifestar politicamente pelo voto ele não encontra qualquer vínculo entre o que fez apoiar seu candidato e as decisões políticas realizadas por seus representantes.

Assim como o trabalhador, não se reconhece na mercadoria que criou (exterioridade), o cidadão eleitor não se reconhece nas decisões tomadas pelo governante em que votou (alienação política).

Esse descompasso entre o motivo que fez o eleitor votar no seu candidato e as tomadas de decisão do candidato eleito, tem como efeito pernicioso o preconceito para com a política que passa a ser, com muita razão, desacreditada pelo cidadão.

O descrédito do cidadão com a política facilita a cooptação do voto (mercadoria) mediante o engodo das propagadas e promessas, pela compra direta do voto ${ }^{5}$ ou pela em razão de vínculos servis e religiosas.

\footnotetext{
${ }^{5}$ No Brasil, tal problemática se evidencia de forma contundente ao se observar que pesquisa estatística informa que $13 \%$ da população nacional admite já ter trocado o voto por emprego,
} 


\section{A mais-valia política}

A mais valia, segundo Marx, é igual à soma de dinheiro originalmente adiantado mais um incremento, consiste em um valor novo (mais valor), que só surge no trabalho humano orgânico, as horas trabalhadas (compra de trabalho).

O dinheiro adiantado ao candidato, nas custosas campanhas eleitorais retorna ao Capitalista que investiu, dinheiro, apoio político ou financiou a campanha política.

Isso porque quando o candidato criado for eleito, o capitalista vai obter a mais valia por meio de contratos com o poder público, cargos e principalmente mediante tomada de decisões e promulgação de leis destinadas a satisfazer interesses individuais em detrimento da coletividade que o efetivamente elegeu. Ou seja, é um investimento que precisa “dar retorno” (D.M.D’).

É um sistema perverso que sufoca qualquer tentativa de uma vertente política diferenciada expor suas ideais, atingir o público em geral e, por conseguinte, ascender ao poder político.

\section{Conclusão}

Tais breves analogias entre a ideologia e o processo de produção capitalista, esmiuçada por Marx, e o ambiente político, em especial, o processo político estatal bem demonstra, a relevância da obra de Marx para estudo da política.

A obra de Marx exige acurada reflexão principalmente a respeito de como resgatar as potencialidades do homem alienado de si mesmo e dos demais seres humanos e, por conseguinte, fomentar a relação humana, a troca de experiências, pontos de vista, discursos, imprescindíveis para o agir político, de modo que, como bem conclui Schütz (2008, p. 87) "se o processo de alienação é, ao mesmo tempo, um processo de perda do ser humano de si, dos outros e da natureza, o processo inverso só pode ser um processo de re-apropriação e de potencialização destas propriedades perdidas".

Do mesmo modo, fica claro a necessidade de superar a eleição e a representação como exclusivos meios de manifestação política no âmbito estatal, pois, a par de tais instrumentos serem instrumentos políticos legitimadores inerentes à democracia, a redução do processo político a tais momentos tem os efeitos nefastos de afastar o cidadão das questões políticas e ao mesmo tempo

dinheiro ou presente. Esta informação vinculada pelo instituto de pesquisa Datafolha mostra que $13 \%$ dos ouvidos admitem já ter trocado voto por emprego, dinheiro ou presente - cerca de 17 milhões de pessoas maiores de 16 anos no universo de 132 milhões de eleitores. Alguns declararam ter cometido essas práticas de forma concomitante. Separados por benefício, 10\% mudaram o voto em troca de emprego ou favor; $6 \%$ em troca de dinheiro; $5 \%$ em troca de presente. Notícia veiculada no site Folha Online 04/10/2009: http://www1.folha.uol.com.br/poder/2009/10/633061-dezessete-milhoes-debrasileiros-admitem-ter-vendido-voto.shtml. 
impedir a discussão de formas alternativas do exercício político, visando reacender o comportamento essencialmente político do homem.

\section{Referências}

DUSSEL, E. Hacia un Marx desconocido. Un comentario de los Manuscritos del 61-63. Mexico: Siglo XXI, 1988.

MARX, K. Os economistas, O Capital Crítica da Economia Política, Volume I, Livro Primeiro, O Processo de Produção do Capital". Tradução Regis Barbosa e Flávio R. Kothe. São Paulo: Nova Cultural, 1996.

. Manuscritos econômico-filosóficos. Tradução e notas de Jesus Ranieri. São Paulo: Boitempo, 2008.

O Capital. Crítica da economia política. Livro I: O processo de produção do capital”. Tradução: Rubens Enderle. São Paulo: Boitempo, 2011.

SCHÜTZ, R. "Propriedade privada e trabalho alienado: desvendando imbricações ocultas", in: Revista Espaço Acadêmico, n 87, ano VIII; ago/2008, p. 82-87.

TAVARES, F. M. M. “A democracia Realizada do Materialismo Histórico: sobre a ditadura do proletariado e sua injustificada omissão nos estudos de teoria democrática contemporânea", in $2^{\circ}$ Simpósio Nacional sobre Democracia e Desigualdade, Brasília 7 a 9 de maio de 2014.

Submissão: 10.10.2018 / Aceite: 15.12.2018. 